\title{
7 Building consensus on sustainable food system assessment
}

\author{
Applying a Delphi survey
}

\author{
Paolo Prosperi, Thomas Allen, and Bruce Cogill
}

\section{Introduction}

Food security and sustainability are at the forefront of political agendas, increasingly stressing the need to improve our understanding and capacity to leverage the linkages between food, health, and the environment. The scientific community has been strongly encouraged by policymakers and various stakeholders to assess the multiple impacts of the food we produce, process, consume, and waste.

Food system approaches specifically aim to step up to this challenge, promoting interdisciplinary and multi-stakeholder analyses of the nexus between diets, the environment, and human health (see also Chapters $10 \&$ 11, this volume). Although there is a host of valuable efforts that identify tools for the assessment of the sustainability of food - both at the national and the international levels, there remains a lack of consensus around metrics to measure sustainable food systems (Perignon et al., 2017). An agreed information system is key for evidence-based knowledge to guide and assess actions. While this need for a limited set of universal indicators may be clear, the method and selection of specific indicators is not. This chapter reports the process used to develop a framework and select a suite of technically and conceptually sound indicators.

In 2013, Bioversity International and the International Center for Advanced Mediterranean Agronomic Studies-Mediterranean Agronomic Institute of Montpellier (CIHEAM-IAMM) with support from the Daniel and Nina Carasso Foundation, have established a multidisciplinary taskforce of experts to identify a shortlist of indicators of 'Sustainable Diets and Food Systems'. Building on past efforts and expertise, in particular on the need to integrate nutritional and agro-biodiversity challenges to the sustainability debate (Fanzo et al., 2012; FAO \& Bioversity International, 2012; Johnston et al., 2014), both institutions have worked to identify a framework and select suitable indicators involved in assessing sustainable food systems.

Building on an existing vulnerability and resilience framework, the team conducted a large expert consultation, through two focus groups and a 
Delphi survey, which allowed a systematic and reproducible identification of indicators for the assessment of sustainable food systems. A Delphi survey is an iterative social science technique for opinion gathering, recognized as an appropriate approach to build consensus and prioritize indicators from different academic fields.

The chapter first discusses the concept of sustainable food systems and presents a conceptual framework that can be adapted to articulate key factors and outcomes of food systems. It then presents the process and synthesizes the main results of the expert consultation, and finally discusses the key lessons learned in designing an interdisciplinary research programme and identifies sustainable food systems metrics adapted to a specific geographical context.

\section{Sustainable food systems: a multidisciplinary concept}

\section{The multidimensional nature of sustainable development}

Sustainable development is multidimensional; it has to satisfy several economic development, social equity, and environmental protection goals. The most frequently quoted definition of sustainability comes from 'Our Common Future', also known as the 'Brundtland Report' (UN, 1987). Human development must meet 'the needs of the present without compromising the ability of future generations to meet their own needs'. When applied to the agricultural and food sector, Conway's (1986) frequently quoted definition of agro-ecosystem sustainability refers to 'the ability of a system to maintain productivity in spite of a major disturbance, such as caused by intensive stress or a large perturbation' (p. 35). As a property of a system, sustainability becomes open to interactions with the external. In other words, sustainability is the dynamic preservation, over time, of the intrinsic identity of the system among perpetual changes (Gallopín, 2003).

Interdisciplinary efforts implicating life science, earth and environmental science, agriculture and nutrition, and social and sustainability science ${ }^{1}$ require a better understanding of the interactions of global change and food security, and not merely integrating multiple bio-physical and socioeconomic factors into the analysis (see also Chapter 2, this volume). There is a need to further cross and link current evidence and knowledge across various disciplines. For instance, in the current context of rapid change, measures of food and nutrition security that only focus on outcomes - such as hunger and malnourishment - are too narrow to capture the dynamics of transformation within food systems.

Multiple factors influence the course of human-environment interactions, which are further complicated by the presence of coevolving causal forces. Research in both the natural and social sciences uses the idea of a system to explain complex dynamics (see also Chapter 4, this volume). A system 


\section{Prosperi, Allen, \& Cogill}

is a network of multiple elements that are interconnected through causal relationships. Modern societies depend on complex systems to provide food. Food systems encompass an array of cyclical activities from soil through to waste recycling and disposal management - including production, processing, packaging and distribution, retailing and consumption - and involve a multitude of actors (Ericksen et al., 2009). Such complexity calls for approaches engaging experts, academics, and multiple stakeholders. For this reason, at every phase of our project, an expert consultation was carried out and the multidisciplinary composition of the expert panel was considered a key element of reliability of the process and constantly monitored.

\section{An integrated set of indicators}

Assessing the sustainability of complex systems thus implies taking into account a wide range of dimensions and indicators. Scholars and policymakers have been calling for the development of an integrated system of food security and sustainability to inform decision-making (Barrett, 2010; Dicks et al., 2013). Sustainability metrics must encompass a wide array of issues relevant to human existence and nature, and they must be useful in guiding the system towards a sustainable trajectory.

Feenstra et al. (2005) define an indicator as 'something used to show the condition of a system' and Gallopín (1997) notes it as an 'operational representation of an attribute (quality, characteristic, property) of a system'. Indicators must, however, be well grounded in science and allow for comparisons across different systems. There is a need for a comprehensive and evidence-based suite of indicators to lead public policy interventions and provide information on adaptive management that is necessary for the practical implementation of sustainability. Indicators, or metrics, gathered as an organized information system and dynamically combined to provide a perspective, target three principal objectives:

- Inform civil society, industry, public officials, and all stakeholders

- Measure impact or progress towards defined goals

- Aid decision-making processes

A sound theoretical framework is the starting point in constructing metrics (OECD, 2008). The selection of sustainability indicators is generally realized following the guidelines of a conceptual framework and a series of criteria related to the availability and quality of the data. However, the selection should be based on what is desirable to measure and not only on which indicators are available. Concurrently, the exercise of developing indicators should also take into account limitations, such as budget constraints, that can make measurement and replication difficult over time. Furthermore, ethics, the transparency, as well as the reproducibility, of the whole exercise is essential in constructing credible indicators. 


\section{Framing workable hypotheses}

\section{Background conceptual framework}

The High Level Panel of Experts on Food and Nutrition Security (HLPE) provided a succinct definition of a sustainable food system by interconnecting the previously coined concepts of food security (UN, 1996) and sustainable development (UN, 1987): 'A sustainable food system (SFS) is a food system that delivers food security and nutrition for all in such a way that the economic, social, and environmental bases to generate food security and nutrition for future generations are not compromised' (HLPE, 2014). Under this definition, the specification of the generational-temporal factor emphasizes the link between food systems and their ability to maintain or enhance their functions over time (Prosperi et al., 2014).

Developing a multidimensional conceptual framework to explore the sustainability of food systems implies specifying what is meant by sustainability. The research approach in this chapter builds on the assumptions that sustainability assessment aims at capturing the ability of a system to maintain and enhance its essential functions over time (i.e. feeding people properly), and that sustainability addresses threats to preserving life support systems, including their capacity to environmentally, socially, and economically withstand and adjust (Allen \& Prosperi, 2016). Since Ericksen's 2008 article, 'Conceptualizing food systems for global environmental change research', it has been often agreed that several global and regional biophysical and socio-economic drivers of change affect the structure and processes of food systems, and thus contribute to, or put at risk, context-specific food and nutrition security outcomes. Fulfilling food system outcomes remains challenging because of socio-economic and biophysical stressors affecting the food system. Food systems are then considered social-ecological systems with economics strongly included in the social dimension - that comprise biophysical and social factors linked through feedback mechanisms (Allen et al., 2014a).

\section{Food systems as social-ecological systems}

Foran et al. (2014) comprehensively synthetize what is generally intended by the term 'social-ecological system' (SES). They note, 'SES visualizes the human-environment interface as a coupled "system" in which socioeconomic as well as biophysical driving forces interact to influence food system (and sub-system) activities and outcomes, both of which subsequently influence the driving forces' (p. 90). Thus, SESs are complex and dynamic systems that are continuously adapting in response to internal or external pressures. They involve societal, human, economic, and ecological subsystems in mutual interactions (Schlüter et al., 2014). 


\section{Prosperi, Allen, \& Cogill}

This understanding of food systems as social-ecological systems helps answer questions about the sustainability problems that affect the functions of the food system. Food and nutrition security is, in fact, considered the principal outcome of any food system and relies on several properties and activities of food systems, namely: producing, processing and packaging, distributing, retailing, and consuming. Those food systems' activities and properties emanate, in turn, in three main sets of outcomes such as food and nutrition security (availability, access, utilization), social welfare, and environmental capital.

Furthermore, various elements of food systems are altered by, and actively impact, the socio-economic and environmental conditions of the system across local, regional, and global levels. Food security depends on multiple bio-physical drivers - such as land and water resources degradation, biodiversity loss, sea-level rising - and economic and social stresses - such as demographic dynamics, technological innovation, economic trends, and social changes - that interact with each other and then impact, individually or concurrently, different aspects of the food system. Such socioeconomic and biophysical drivers might impact food security directly or indirectly, positively or negatively, and change over time; when a food system fails to deliver people food security, considered as its primary outcome, the system can be considered as vulnerable.

Therefore, food systems can be vulnerable, and resilient, to a set of stressors (Adger, 2006) such as environmental pressures, socio-economic instabilities and institutional and policy factors (Turner et al., 2003). The identification of vulnerability and resilience variables can help to proxy the metrics of food systems. These variables will be determinant in explaining if the system is able to meet over time its foremost outcome, that is, ensuring food and nutrition security for all. They will point to the social, economic, and environmental elements of the system which condition, and can be leveraged to guarantee, the availability of healthy and accessible food for human nutrition.

\section{Vulnerability and resilience as properties of food systems}

Sustainability addresses threats to preserving life support systems, including their capacity to withstand and adjust. It is then crucial to assess stocks of, and changes in, human and natural assets. Derived from sustainability sciences (Turner et al., 2003), the vulnerability and resilience approach within the social-ecological systems frameworks, proved relevant to analyse the sustainability of critical food and nutrition security outcomes (Prosperi et al., 2014; Allen \& Prosperi, 2016; Prosperi et al., 2016).

Vulnerability is the degree to which a system is likely to experience harm due to exposure to a perturbation or stress. Resilience represents the ability of a system to anticipate, absorb, accommodate, or recover from the effects of a potentially hazardous event, in a timely and efficient manner, through 
ensuring the preservation, restoration, or improvement of its essential basic structures and functions. Since Turner et al.'s 2003 'A framework for vulnerability analysis in sustainability science', (2003), a strong effort has been made to encourage the consideration of vulnerability and resilience research in sustainability science. Theories of vulnerability and resilience proved helpful to understand the complex dynamics involving socioeconomic and biophysical aspects, and to implement sustainable development strategies and research programmes.

Building on the vulnerability and resilience theoretical framework, a causal-factor approach allows studying the sequential pathway through which food systems' key outcomes can be threatened. Exposure, sensitivity, and resilience ${ }^{2}$ become key food system properties defining its capacity to ensure food and nutrition security over time (Figure 7.1). Understanding the causal mechanisms that regulate the interactions between drivers of change and food and nutrition security issues can help in analysing and interpreting available information, developing metrics, and anticipating new hazards and changes. The investigation of causes, effects, and responses to socio-economic and biophysical changes can provide analytical tools to further understand the problems that affect the sustainability of the food system. The conceptual hierarchical framework developed has been operationalized for modelling the complex relationships between food and nutrition security and sustainability in a specific geographical context, developing indicators of sustainable food systems (Allen et al., 2014b). To

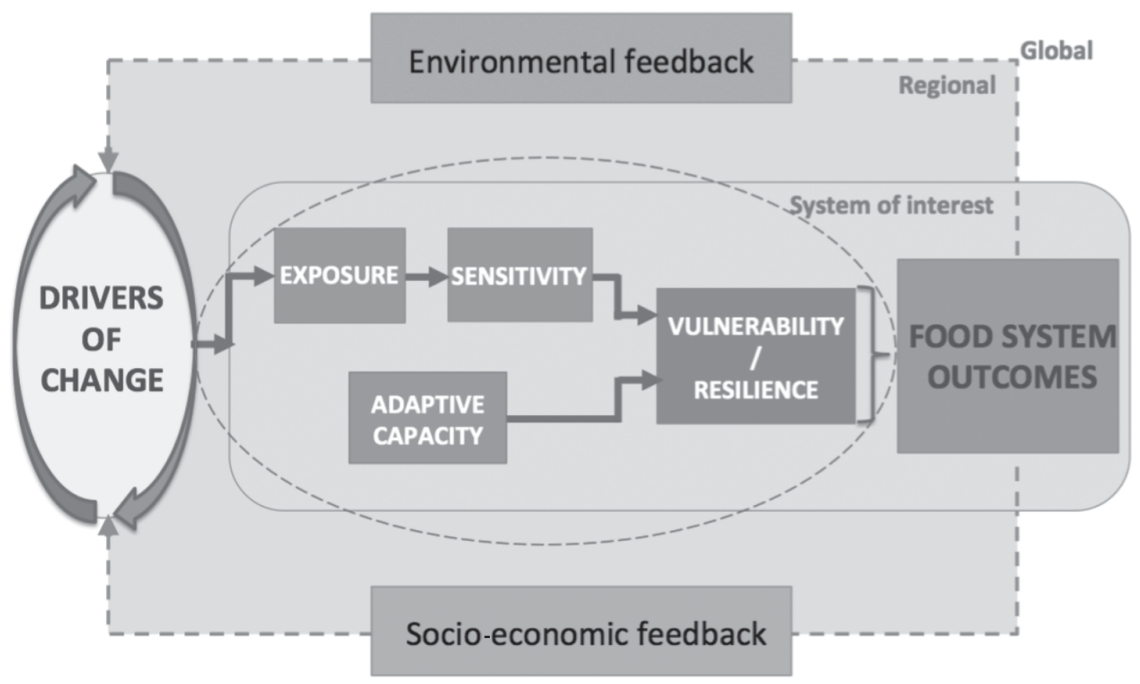

Figure 7.1 A sustainable food system framework.

Source: Adapted from: Allen and Prosperi, 2016. 
illustrate the application of the framework, the approach was applied to countries in the Mediterranean region.

\section{Discussing and selecting indicators}

\section{Focus groups and the Delphi study: an expert-based approach}

Sustainability can have different understandings and participatory approaches might be particularly appropriate to identify and share the conditions, priorities, and resource constraints crucial to sustainability assessment. Participatory processes with stakeholder involvement are often acknowledged to be crucial for sustainability assessment. Implication of key actors and disciplines should be embedded in all steps, leading to a coproduction of knowledge from problem definition towards local solutions (see also Chapters 2, 3, 5, \& 8, this volume). Concurrently, food system practitioners call for appropriate metrics from researchers and the identification of indicators for policymaking needs to be traceable, evidence based, and scientifically sound in order to guarantee transparency in decisionmaking and effectiveness of evidence-based policy (Bell \& Morse, 2013). Qualitative consultation methods, such as focus group techniques and Delphi surveys, allow for a robust participatory process and satisfactorily shared results. Specifically, our project's main outcome consists of gathering and synthesizing scientific knowledge for the assessment of sustainable food systems, thus it involves mainly scientists and academics (from several disciplines) in order to provide practitioners with suitable metrics.

Building on multidisciplinary ${ }^{3}$ and interactive research practices, the methodology developed in the project is composed of ten steps (Figure 7.2), from the construction of a global conceptual framework to the identification of a reduced suite of context-specific indicators: (1) identification of a global food system conceptual framework; (2) definition of the case study area; (3) identification of essential drivers of change; (4) identification of essential food system outcomes; (5) development of a set of context-specific causal models; (6) identification of a large set of indicators; (7) design of the Delphi survey; (8) elicitation of feedback from two focus-group sessions; (9) the Delphi survey; and (10) identification of the reduced suite of indicators.

Two exploratory focus groups were gathered and facilitated before the Delphi process to (a) discuss the framework, (b) test the questionnaire, and (c) comment on an initial list of 136 indicators taken from the literature. A Delphi survey is an acknowledged research technique whose aim is to obtain a reliable group opinion from experts (Allen et al., 2019). It is a group interaction process directed in iterative rounds of opinion collection and feedback and provides a systematic method to involve experts in problem analysis and discussion on complex issues, helping convert diverse views and opinions into one or more communal notions through an iterative feedback process (Allen et al., 2019). The survey was conducted via email 


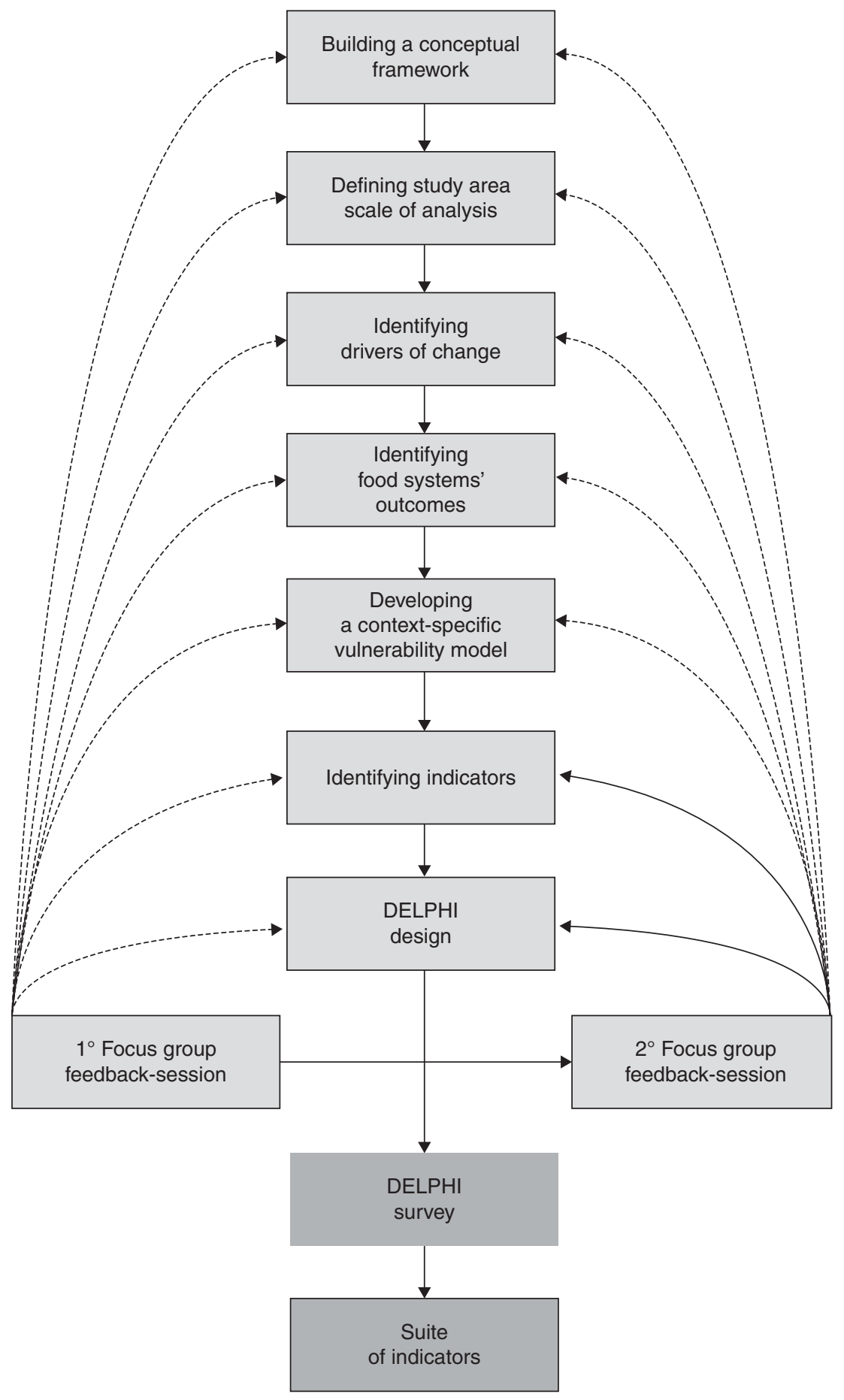

Figure 7.2 A sequence of 10 steps.

Source: Authors' elaboration modified from Allen et al., 2019. 
and SurveyMonkey®, a web-based survey platform, with the aim of further discussing the survey outcomes in an ex-post workshop with all participants.

\section{Identification of eight selected causal models of vulnerability and resilience}

Following an extensive review of literature, the vulnerability/resilienceadapted framework for the global food system (Figure 7.1) was proposed as the basis for discussion during a first focus group with a panel of multidisciplinary experts. The vulnerability/resilience framework was proposed as suitable for our research as it was regularly quoted by multiple sources discussing food systems sustainability and presented a broad hierarchical system of information that could serve as a starting point for discussion. The identification of a causal pathway (adapted from Metzger \& Schroeter, 2006) allowed locating the role of the three variables of exposure, sensitivity, and resilience.

Following the first focus group, eight specific causal models of vulnerability and resilience were selected within a larger set of models. Shaping the interactions where a set of drivers of change - that is, water depletion; biodiversity loss; food price volatility; changes in food consumption patterns - directly affect a set of food and nutrition security outcomes at a sub-regional level - that is, nutritional quality of food supply; affordability of food; dietary energy balance; satisfaction of cultural food preferences. Those drivers of change, as well as food and nutrition security outcomes and the related interactions, are specific to the geographical area of the Latin Arc within the Mediterranean region (for a justification of the geographical scale and information on local food system characteristics see Allen and Prosperi, 2016). Each interaction was disentangled in exposure, sensitivity, and resilience. In particular, these sets of characteristics are indicating how changes in water, biodiversity, food prices, and food consumption patterns are transmitted through the regional food system. This includes the sequence of events and the scale of interactions: (a) how the regional food system is sensitive to these changes; and (b) the subsequent adaptive capacity of the food system (see Box 7.1 for brief definitions of these main issues and drivers; see Figure 7.3 and Table 7.1 for both a graphic and an analytical description of the eight causal dynamics).

Box 7.1 Proposed drivers and issues

\section{Drivers}

Water depletion is 'a use or removal of water from a water basin that renders it unavailable for further use' (Molden, 1997). Water availability 
is closely related to climate change trends altering precipitation patterns and rainwater (SCAR, 2011). It is also related to agrofood patterns and the use and concentration of agrochemicals, impacting the quality of water, further contributing to water scarcity.

Biodiversity loss is defined as 'the long-term or permanent qualitative or quantitative reduction in components of biodiversity and their potential to provide goods and services, to be measured at global, regional and national levels' (Convention on Biological Diversity, 2004). Biodiversity loss is cogenerated by climate change, environmental depletion, and water stress. It is strongly related to modern food production and consumption patterns (Altieri, 2000) that have become more intensive and homogenizing.

Food price volatility refers to large and atypical 'variations in agricultural prices over time' (FAO, 2011). Climate change, changing trade patterns, new dietary trends, and growing demand for biofuels are often invoked as causes of food price volatility. Speculation on commodity markets and reduction of food stocks are also crucial determinants of price variations (Robles et al., 2009).

Changes in food consumption patterns refer to the changing structure of global food consumption, related to changing dominant values, attitudes, and behaviours (Kearney, 2010; Johnston et al., 2014). Individual food consumption patterns - that is, diets - are the results of changes in culture, social values, and representations attached to food consumption, driving effectively behavioural changes and resulting in modified diets. The global changes in food consumption patterns - with a shift to more animal-sourced products, and foods high in fat, energy, and salt (Drewnowski and Popkin, 1997) are largely driven by demographic factors and income growth, and are related to changes in activity levels, lifestyle, globalization, urbanization, markets, changes in occupational status and employment distribution, and more effective dissemination of information (Meade, 2012).

\section{Food and nutrition security issues}

Nutritional quality of the food supply refers to the nutritional composition of the food products on the market (Observatoire de la qualité de l'alimentation - Oquali, Institut national de la recherche agronomique - INRA). The improvement of the nutritional quality of the food supply is one of the eight specific actions defined by the Word Health Organization European Action Plan for Food and Nutrition Policy 2007-2012. A balanced diet is achieved through personal habits but also requires that the foods eaten by consumers have a satisfactory nutritional composition. 
Affordability of food is defined as 'the purchasing power of households or communities relative to the price of food' (Ingram, 2011). It refers to the 'economic access' to food (Foran et al., 2014). Affordability is about food being available at prices that people can afford to pay, and in particular, whether low-income consumers can afford to buy enough nutritious and healthy food to meet basic needs (Barling et al., 2010).

Dietary energy balance refers to the balance between energy intake and energy expenditure (Patel et al., 2004). Excessive fat accumulation is acknowledged to be a risk factor for various health problems, including cardio-vascular diseases, diabetes, cancers, and osteoarthritis (WHO, 2008). A range of environmental, social, and behavioural factors interact to determine energy intake and expenditure, such as sedentary lifestyles, consumption of and heavy marketing of both energy-dense foods and fast food outlets, adverse social and economic conditions, the consumption of high-sugar drinks, etc. (Swinburn et al., 2004).

Cultural food preferences are powerful environmental factors related to social background and behaviours, which contribute to food choices and intakes. Recognizing ethnic and cultural food preferences and changes, compatible with nutritional requirements, is essential for food acceptance and well-being. Food preferences, socially or culturally determined, are now recognized as a key consideration in food security.

Next, a large list of indicators was identified by the research team and discussed in a second focus group with the same expert panel. Additional indicators were proposed by the experts, while some were deleted, and the process resulted in a shortlist of 136 indicators. Both the suggested framework and the shortlist of indicators were then submitted to a large panel of experts for further discussion though a Delphi consultation.

\section{Identification of indicators}

Following the protocol of the Delphi survey (Allen et al., 2019), 52 experts from more than 40 academic and policy institutions worldwide were asked to discuss and refine the framework and the underlying assumptions, and to test the framework by selecting proxy indicators.

First, an extensive list of 213 potential experts was developed by reviewing academic publications. An electronic letter of invitation was sent to the identified experts to explain the goals and protocol of the study, and permitted potential participants to self-estimate their expertise and aptness to the study. Two weeks later, a general email was sent to all identified experts containing a link to the questionnaire and background material. 


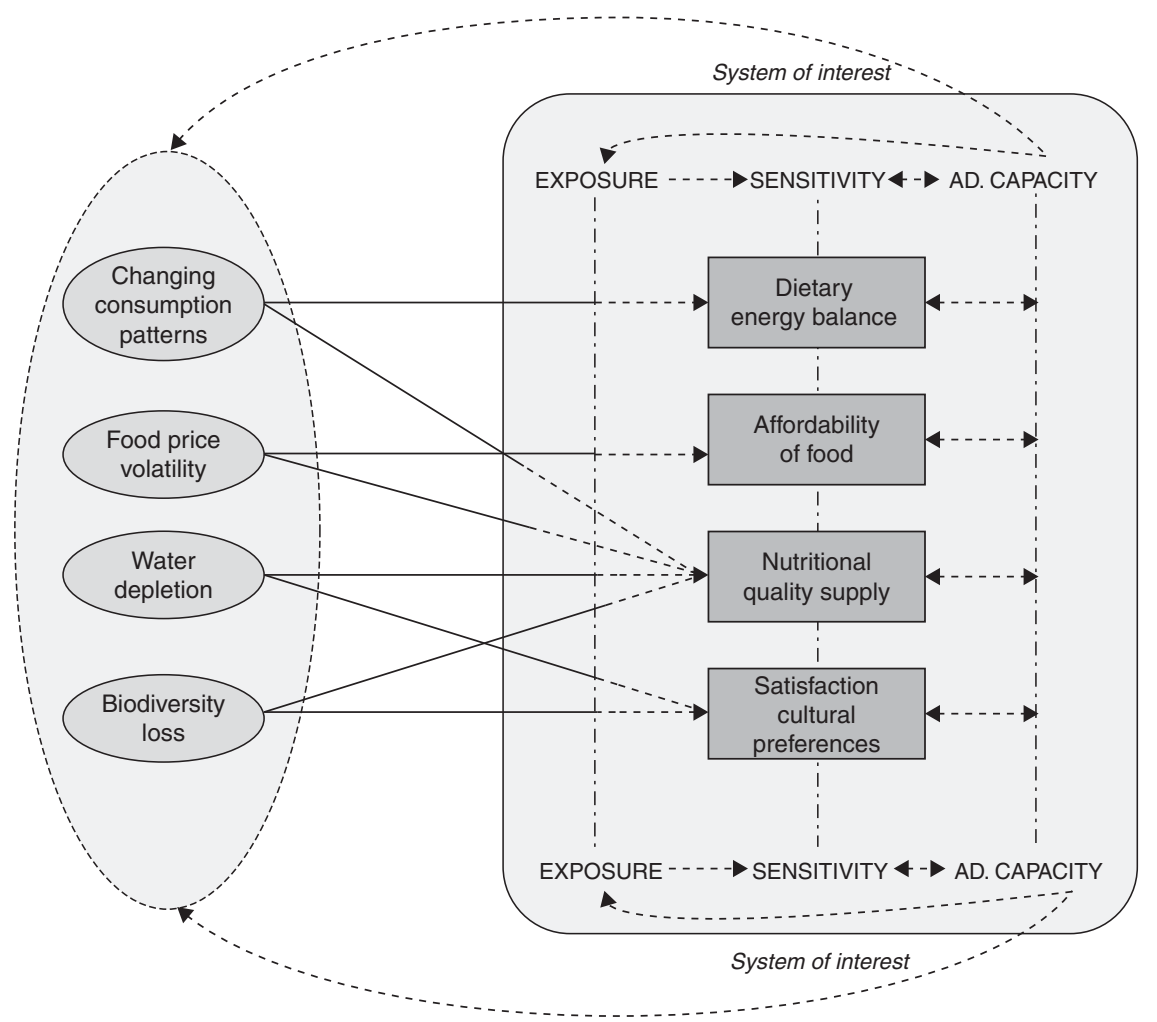

Figure 7.3 Interacting drivers and outcomes - graphic description.

Source: Allen and Prosperi, 2016.

This material included a document explaining the conceptual background, the specific aim and purpose of the Delphi study, and the summary details of the proposed indicators.

After each round a statistical analysis was run to provide participants with feedback to revise the questionnaire. Feedback reports providing each participant with the group results and their individual previous responses were sent via email after each of the three Delphi rounds. Overall, the final results were presented four months after sending the first letter of invitation. In each round, participants were asked to select their preferred indicator for each of the 24 components of the framework from a menu of five to eight preselected indicators (see Table 7.2). Twenty-four indicators are the desired outcomes from the selection of three indicators (i.e. exposure, sensitivity, resilience) per interaction analysed (i.e. eight selected interactions between drivers of change and food security issues). Participants had the opportunity to propose new indicators. Indicators that did not receive any 
Table 7.1 Interacting drivers and outcomes - analytical description

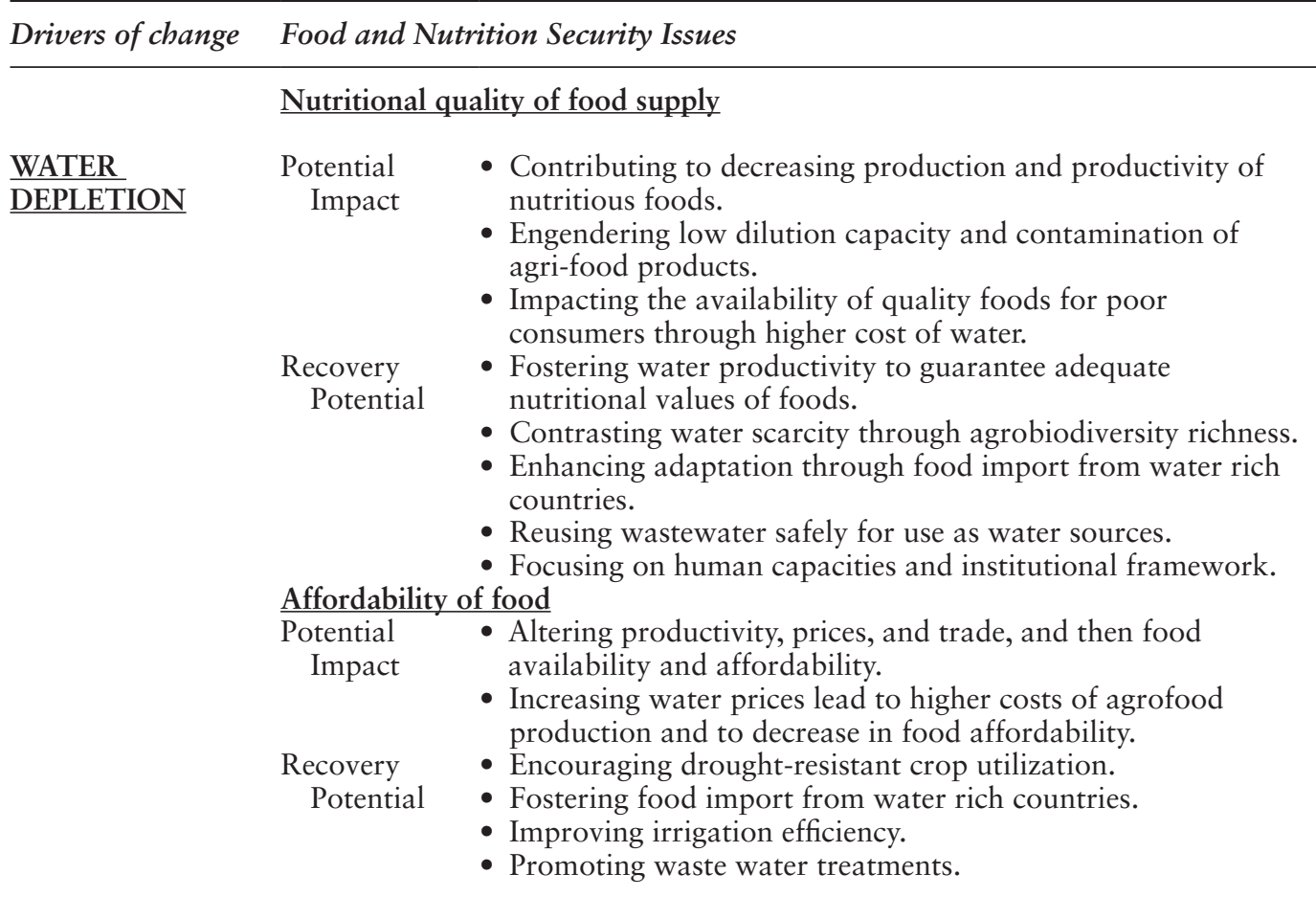

SCAR, 2011; Wood et al., 2010; PARME, 2011.

SCAR, 2011; UNWATER, 2014.

Wood et al., 2010; SCAR, 2011.

Hellegers et al., 2008; Waughray, 2011. 
Nutritional quality of food supply

BIODIVERSITY Potential - Shifting to ecologically simplified systems based on cereals,

LOSS Impact

Recovery

Potential

which contributes to poorly diversified diets.

- Hampering food systems responses against climate change, with consequent impact on productivity.

- Increasing the dependency on global varieties on external inputs.

- Promoting agrobiodiverse systems for ecosystem services, food security benefits (nutritional value of foods), the

viability of agricultural systems, and long-term productivity.

- Fostering organic farming.

Satisfaction of cultural food preferences

Potential

Impact

- Putting at risk cultural traditions and preferences, linked to regional varieties and diets.

- Homogenizing food production.

- Contributing to reduce the enormous amount of information on nutritional and health benefits of the foods that shape the food cultural preferences of people.

- Decreasing food biodiversity, which could result in the loss of unique and traditional foods.

Recovery

Potential

- Knowing how to prepare a more varied diet can influence consumption of different food products.

- Providing more varied and tasteful diets.

- Enhancing and keeping traditional food cultures.

FOOD PRICE Potential

VOLATILITY Impact
- Impacting food production and consumption.

- Altering food supply towards disadvantaged groups.

- Leading to profound changes in the composition and availability of food supplies.

- Hampering the present agrofood system supply, strongly interlinked with the fossil fuels system.
Arimond et al., 2010; SCAR, 2011.

Thrupp, 2000; Reidsma \& Ewert, 2008 .

Kearney, 2010; SCAR, 2011.

Termote et al., 2010; Johnston et al., 2014.

DEFRA, 2008; SCAR, 2011. 


\begin{tabular}{|c|c|c|}
\hline \multirow[t]{2}{*}{ Drivers of change } & \multicolumn{2}{|c|}{ Food and Nutrition Security Issues } \\
\hline & $\begin{array}{l}\text { Recovery } \\
\text { Potential }\end{array}$ & $\begin{array}{l}\text { - Enhancing dietary diversity for avoiding dependency on few } \\
\text { groups of foods. } \\
\text { - Fostering local provisioning and production, less involved in } \\
\text { price variations. }\end{array}$ \\
\hline & $\frac{\text { Affordability }}{\text { of food }}$ & \\
\hline & $\begin{array}{l}\text { Potential } \\
\text { Impact }\end{array}$ & $\begin{array}{l}\text { - Impacting household incomes and purchasing power. } \\
\text { - Affecting agrofood productivity, and therefore food } \\
\text { affordability and availability. } \\
\text { - Exacerbating economic shocks for the poor, who depend on } \\
\text { wages and the rest of the economy. } \\
\text { - Shifting purchasing strategies to lower quality products. }\end{array}$ \\
\hline & $\begin{array}{l}\text { Recovery } \\
\text { Potential }\end{array}$ & $\begin{array}{l}\text { - Fostering food industry's focus on consumers and their need } \\
\text { - Sor 'affordable food of high quality and diversity'. } \\
\text { the same caloric and nutritional requirements. } \\
\text { - Implementing food policies for diversifying supply sources } \\
\text { through different strategies (subsidies, food stamps). } \\
\text { - Promoting diversity in food consumption patterns. }\end{array}$ \\
\hline & 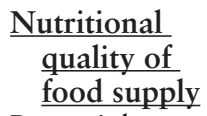 & \\
\hline \multirow{5}{*}{$\begin{array}{l}\text { CHANGES } \\
\text { IN FOOD } \\
\text { CONSUMPTION } \\
\text { PATTERNS }\end{array}$} & Potential & - Influencing food industry production patterns, overall food \\
\hline & Impact & security, and nutritional characteristics of diets. \\
\hline & & $\begin{array}{l}\text { - Shifting the demand towards cereals, simple sugars, animal } \\
\text { products, and highly processed foods. }\end{array}$ \\
\hline & $\begin{array}{l}\text { Recovery } \\
\text { Potential }\end{array}$ & $\begin{array}{l}\text { - Improving the understanding of the determinants of } \\
\text { consumer choices. }\end{array}$ \\
\hline & & $\begin{array}{l}\text { - Empowering consumers' choice for healthy and safe } \\
\text { provided food. } \\
\text { - Engendering consumption patterns cognizant of the impact } \\
\text { of food choice on health. }\end{array}$ \\
\hline
\end{tabular}

Wood et al., 2010; HLPE, 2011; SCAR, 2011; Regmi \& Meade, 2014.

European Technology Platform, 2008; Brunori \& Guarino, 2010.

European Technology Platform, 2008; Brunori \& Guarino, 2010; SCAR, 2011; UNEP, 2012.

SCAR, 2011; Allen et al., 2014. 


\section{Dietary Energy}

\section{Balance}

Potential

Impact

- Increasing consumption of fats, sugars, sweeteners, animal products, highly processed foods, and in fast foods and vending machines products.

- Decreasing consumption in plant proteins and of home-prepared foods.

- Strengthening 'obesogenic' environments with little energy expenditure and sedentary lifestyles.

- Altering frequency and the amounts consumed of foods.

- Decreasing dietary diversity.

- Fostering public awareness for healthier diets through campaigns and community movements.

Recovery

Potential

- Enhancing cultural knowledge on preparing varied diets and on nutritional and health benefits of the foods.

- Promoting weight loss and metabolic health through appropriate changes in the gut microbiota.

- Supporting guidelines on dietary strategies to counteract overweight and obesity.

PARME, 2011; SCAR, 2011; UNEP, 2012.

Barling et al., 2010; Termote et al., 2010; Lopez-Legarrea et al., 2014. 
participant preference were excluded from the following rounds. New indicators were added if at least two participants proposed the same, or a similar, variable. A 'Don't know' option was always included in the menu to allow experts to express their lack of knowledge on a specific component.

After a first open-ended round, panellists were presented with the opportunity to justify or amend their first choices. Succeeding rounds have been designed to bring the group to focus or consensus. An upgraded framework and a restricted set of indicators were reached, after three rounds, from this consultation process. The Delphi study revealed low-, medium-, and high-consensus and a majority-level on indicators in 75 per cent of the interactions out of the 24 initial ones. The results obtained in terms of global response, expert participation rates, and consensus on indicators, were then satisfactory. Also, experts confirmed with positive feedback the appraisal of the components of the framework.

Consensus was finally reached in round three for 14 of the 24 desired indicators (see Table 7.2). Eight indicators have met the high threshold consensus criteria ( 80 per cent), three other indicators have met the medium threshold consensus criteria ( 70 per cent), and another three have achieved the low threshold consensus criteria (60 per cent). Four indicators have been selected by the majority of the participants (above 50 per cent). For five dimensions (out of 24), clear bi-dimensionality can be reported (two indicators above 35 per cent). In some of these cases, several experts recommended constructing a composite indicator. Three dimensions remained unresolved with a wide dispersion of expert opinions among indicators and little improvement of the consensus through the rounds (see final round results in Table 7.2).

The chosen list of 14 indicators includes:

1. Water Footprint of nutrient-dense foods [cubic metres $/ \mathrm{kg}$ ]

2. Intensity of use of actual water resources [\%]

3. Irrigation Water Efficiency Index [\%]

4. Water Footprint for an average diet [cubic meters/yr]

5. \% of total acreage of top 5 varieties

6. Nutritional Functional Diversity

7. Crop Agrobiodiversity Factor

8. $\%$ of diets locally produced

9. \% of nutrient intakes (Vit. A, Zn, I, Fe) from 10 most volatile foods

10. Household Dietary Diversity Score

11. \% of food household expenditure

12. Sensitivity to price volatility

13. Food Purchasing Power Index

14. Household Dietary Diversity Score

Prevalence of overweight and obesity is just below minimum threshold consensus criteria (60 per cent). 
Table 7.2 Level of consensus reached by indicator

\begin{tabular}{|c|c|c|c|}
\hline & & Nutritional Quality of Food Supply & Affordability of Food \\
\hline \multirow[t]{4}{*}{ Water Depletion } & Exposure & $75 \%$ Water Footprint of nutrient-dense foods & $86 \%$ Water Footprint for an average diet \\
\hline & Sensitivity & $61 \%$ Intensity of use of actual water resources & $53 \%$ Price index for 10 most water-demanding foods \\
\hline & Resilience & 83\% Irrigation Water Efficiency Index & $\begin{array}{l}47 \% \text { Cross-price elasticity of demand of high/low } \\
\text { water demanding foods }\end{array}$ \\
\hline & & Nutritional Quality of Food Supply & Satisfaction of Cultural Food Preferences \\
\hline \multirow[t]{7}{*}{ Biodiversity Loss } & Exposure & $64 \%$ & $47 \%$ \\
\hline & & $\%$ of total acreage of top 5 varieties & Import Dependency Ratio \\
\hline & Sensitivity & $83 \%$ & $72 \%$ \\
\hline & & Nutritional Functional Diversity & $\%$ of diets locally produced \\
\hline & Resilience & $89 \%$ & $53 \%$ \\
\hline & & Crop Agrobiodiversity Factor & $\begin{array}{l}\text { Integration of biodiversity considerations in } \\
\text { business }\end{array}$ \\
\hline & & Nutritional Quality of Food Supply & Affordability of Food \\
\hline \multirow[t]{7}{*}{ Price Volatility } & Exposure & $72 \%$ & $81 \%$ \\
\hline & & $\%$ of nutrient intakes from 10 most volatile foods & $\%$ of food household expenditure \\
\hline & Sensitivity & $47 \%$ & $86 \%$ \\
\hline & & Price elasticity of 10 most nutrient-dense foods & Sensitivity to price volatility \\
\hline & Resilience & $92 \%$ & $53 \%$ \\
\hline & & Household Dietary Diversity Score & Presence of safety net programmes \\
\hline & & Nutritional Quality of Food Supply & Dietary Energy Balance \\
\hline \multirow{6}{*}{$\begin{array}{l}\text { Change in Food } \\
\text { Consumption } \\
\text { Patterns }\end{array}$} & Exposure & $64 \%$ & $47 \%$ \\
\hline & & Food Purchasing Power Index & Caloric share of ready-to-consume products \\
\hline & Sensitivity & $83 \%$ & $58 \%$ \\
\hline & & Household Dietary Diversity Score & Prevalence of overweight and obesity \\
\hline & Resilience & $28 \%$ & $28 \%$ \\
\hline & & $\begin{array}{l}\% \text { of public expenditure on food subsidies AND } \\
\text { Existence of national dietary guidelines }\end{array}$ & $\begin{array}{l}\text { Existence of policy plan for overweight/obesity } \\
\text { AND Funding allocated to nutrition education }\end{array}$ \\
\hline
\end{tabular}




\section{Lessons learned}

\section{Discussing implementation of the framework}

This study aims at filling the theoretical and methodological gaps in quantitative assessment of sustainable food systems, combining a theory-driven approach with expert judgment, rather than a data-driven process. Since 'what is badly defined is likely to be badly measured' (OECD, 2008), efforts were concentrated on the operationalization of theories (vulnerability and resilience) in order to build a solid, common and replicable basis for defining a metric system. Within a broad systemic approach, the research attempted to operationalize the framework for the assessment of the sustainability in food systems through multidisciplinary and multi-stakeholder consultation. This research effort is provided to the scientific community, practitioners, or policymakers who might be interested in assessing and disentangling the characteristics of a given food system through the operationalization of this dynamic framework.

First, one challenge was to identify pathways leading to vulnerability, and the characteristics and opportunities ensuring resilience of the food system in a context of change. Resilience and vulnerability are considered problematic to operationalize through precise assessment methods due to their theoretical and multidimensional nature. It emerged from the workshop convened after the Delphi survey that participants had sometimes an incomplete understanding of the proposed framework. This is a shortcoming of the operationalization of the vulnerability and resilience framework as it has been already observed by working with practitioners (Foran et al., 2014) and it can have an impact on the indicator selection.

Second, several participants would have liked to have seen other food systems' outcomes than food and nutrition security issues considered. As it was already emerging from the Delphi consultation, environmental and social outcomes are standing out as crucial elements to consider and include in the assessment exercise. It was highlighted that this would be more in line with the general perception of what sustainability means: 'People think about sustainability as an outcome'. 'People want a descriptor of a state rather than the prediction of a state'. Furthermore, some experts would also have liked to complement the list of food and nutrition issues, adding elements such as 'dietary quality'.

The use of the food system framework developed was nevertheless acknowledged to anticipate and predict possible future outcomes of the food systems. A participant presented the framework as 'a model', highlighting the causal pathway that it aimed at providing. Some participants recalled that 'understanding what is driving the outcomes is important'.

\section{Informing policy towards sustainable food systems}

Assessing issues related to sustainability problems, with the goal of informing the decision-making process, has a number of critical implications. There 
is, in fact, a growing debate about the importance of the role, utility, adoption, focus, and final goals of the sustainability indicators. There are several different ways to interpret indicators and select data. It is therefore important to know how the information provided by the indicators is going to be transferred to policymakers, and what the actual aims are of using the indicators. Aggregation of data can strongly alter the messages for policymakers, and several studies demonstrate that often the indicators that have been prepared in an appropriate technical manner are not actually applied nor do they have a real impact on policymaking (Bell \& Morse, 2013; see also Chapters 5 \& 11, this volume).

Referring to the European Union institutions, Sébastien and Bauler (2013) proved also the need for a greater involvement of the actors of the political and institutional contexts where indicators have to be identified and applied. A strong and active involvement of the local/community stakeholders is key to designing a set of metrics that will be useful to measure real progress and gaps towards the sustainability of food systems (see also Chapter 6, this volume). Moreover, the theories of vulnerability and resilience are often acknowledged as particularly effective by the scientific community for both conceptual and methodological aims of research, while development practitioners find those theories difficult to operationalize, with local actors at a context-specific level, for their complex and systemic nature (Foran et al., 2014). However, practitioners consider metrics as crucial tools to measure development and sustainability goals achieved in a given food system (Dicks et al., 2013).

Another important question is the type of policymakers targeted and the role of the media in informing policymakers. 'Who are the stakeholders we need to influence?' 'Who are the policy makers?' An expert suggested that there may be different goals for policymakers at different levels, for example, (1) 'to communicate to high-level policy makers and media about the overall state of the food systems by focusing on food system outcomes', and that (2) '[i]mplementing diagnostic models and causal analyses can help food-focused policy-makers as well as other types of policy-makers'.

\section{Conducting a Delphi survey}

A number of lessons can be drawn in terms of practice to enhance validity, replicability, participation, and consensus for further Delphi studies:

- It is important to demonstrate to participants the benefits for society and science of the proposed survey, while considering the potential shortcomings of this approach

- Given the diversity of views and understandings of what sustainability means, discussions need to be guided through structured and replicable methods, in particular if metric systems are the final outcome of the discussions. In this regard, iterative approaches are appropriate 
- Transparency and multidisciplinary participation are crucial in the development of sustainability indicators, but present the risk of weaker consensus. Therefore, allowing a longer time-frame for decision-making may involve trade-offs

- Agreeing on a detailed background framework is essential for the development of indicators, but unlikely to happen if the framework is either too specific or not adaptable. The objectives of informing local stakeholders and aiding decision-making should be the driving principles when reducing the framework to its core elements, prioritizing short-term decision efficiency over long-term sustainability

- Having institutional support could help participants feel the beneficial purpose for society instead of fostering an exclusively profit-seeking aim for the team running the study

- If possible, holding a face-to-face meeting would help to dissipate remaining uncertainties and possible misunderstandings. For instance during the Delphi survey it was mentioned that a technical workshop (actually held in Montpellier, France, on November 2014) would have been convened at the end of the Delphi study and that participants would have been invited for further scientific discussion and involvement

- For selecting appropriate sustainable food system metrics, it is crucial to convene a diverse and appropriate expert team with a very good knowledge and understanding of the problems of the sustainability of the food systems

- Gathering two preliminary focus-group sessions as a pilot application for a Delphi helps to conceive properly the first questionnaire, managing, motivating, and administrating feedbacks

- Sending qualitative personalized feedback with comments, explanations, and suggestions from the experts enables real interaction of the group

- The use of Internet technology allows for the opportunity to consult large, geographically dispersed, expert communities

- Providing relevant but not overloaded scientific content and materials to participants allows them to be informed participants

- Structuring the survey makes each round progressively less time-consuming

- Further efforts are needed to build context-specific vulnerability and resilience frameworks that are adaptable and suitable to effectively identify metrics with both researchers and development practitioners

\section{Conclusion}

The 'Metrics of Sustainable Diets and Food Systems Project', led jointly by Bioversity International and CIHEAM-IAMM, has contributed to the exploration of assessment approaches to develop information systems for sustainable food systems. The broad vulnerability and resilience framework has been proposed to capture the food system as a whole and identify 
key system elements that policy can control or mitigate. Food systems are networks in which components are connected to each other through causal pathways operating at different geographical or time scales. Distinguishing three components - exposure, sensitivity, and resilience - allows the model to specify which attributes need to be measured and how to structure the different indicators in a coherent assessment framework. The operationalization of this framework in a limited geographical area (i.e. the Latin Arc in the Mediterranean region) allowed for modelling dynamic interactions specific to the analysed region.

An innovative participatory research methodology - a Delphi survey has implemented discussion of this framework, guiding the identification of indicators. It provided the systematic and scientific approach to propose a first core set of indicators to assess the sustainability of diets and food systems. The Delphi method, with the participation of several experts coming from different disciplines and institutions, provided practitioners, and eventually policymakers, with a transparent view of the process of developing sustainability metrics for food systems. The participation of experts was included all along the theoretical and operational research process. Before the Delphi process, two focus group feedback sessions with experts have contributed to improving the theoretical framework and tailoring the questionnaires. Expert opinion was crucial from the beginning to select the most urgent food system's drivers of change, and food and nutrition security issues, as well as to validate the dynamic interactions proposed in the framework. Also, with particular regard to the questionnaire, focus group experts helped finding the best way to address Delphi participants with questions on the set of metrics, in order to make the questionnaire more understandable and, therefore, to make the iterative process successful in terms of response rate.

This exercise has shown what is required to construct a shared information system for the assessment of sustainable food systems, replicable at different scales: (a) developing a sound and general conceptual framework of food systems outcomes and drivers, based on theories and evidence-based observations at both the global and local scale; (b) facilitating the involvement of experts in knowledge production to provide critical feedback and create consensus; and (c) identifying context-specific metrics and guaranteeing a traceable and reproducible selection process.

The process resulted in consensus on 14 indicators. Moving forward, an enhanced understanding of the availability of data to compute these indicators and of the interpretation of their results is needed.

\section{Acknowledgements}

This research process was mainly realized in 2013-2014 within the framework of a scientific collaboration between the CIHEAM-IAMM (Montpellier, France) and Bioversity International (Montpellier and Rome): Paolo Prosperi was affiliated to CIHEAM-IAMM, Thomas Allen and Bruce Cogill to 


\section{Prosperi, Allen, \& Cogill}

Bioversity International. Thomas Allen's work was supported by the Daniel and Nina Carasso Foundation (Grant Number: 00030240) and CGIAR Research Programme Agriculture for Nutrition and Health. The Daniel and Nina Carasso Foundation had no role in the design, analysis, or writing of this chapter. The authors would like to thank the 52 experts for their participation and input in the Delphi survey.

\section{Notes}

1 Sustainability science was introduced in 2001 by Kates et al. (2001).

2 Exposure is the nature and degree to which a system is likely to be affected by the occurrence of a change. Sensitivity is the degree to which a system is affected either adversely or beneficially, by a change. Resilience is the ability of a system to anticipate, absorb, accommodate, or recover from the effects of a potentially hazardous event in a timely and efficient manner, through ensuring the preservation, restoration, or improvement of its essential basic structures and functions (IPCC, 2012).

3 This project implies a multidisciplinary approach since it involves participation of academic experts from different disciplines. However it does not imply - at least at this stage - a transdisciplinary approach, since local practitioners or stakeholders are not directly involved in the participatory research process for indicators, but the effort consists of providing practice actors with metrics obtained through traceable and scientific knowledge-synthesis methods. Nevertheless, the research process was built on literature taking Mediterranean policy reports as main references.

\section{References}

Adger, W.N. (2006) Vulnerability. Global Environmental Change. 16(3), pp. 268-281.

Allen, T. \& Prosperi, P. (2016) Modeling sustainable food systems. Environmental Management. 57(5), pp. 956-975.

Allen, T., Prosperi, P., Cogill, B., \& Flichman, G. (2014a) Agricultural biodiversity, social-ecological systems and sustainable diets. Proceedings of the Nutrition Society. 73(4), pp. 498-508.

Allen, T., Prosperi, P., \& Cogill, B. (2014b) Metrics of sustainable diets and food systems. Workshop Report. Montpellier, France, Bioversity International \& CIHEAM-IAMM.

Allen, T., Prosperi, P., Cogill, B., Padilla, M., \& Peri, I. (2019) A Delphi approach to develop sustainable food system metrics. Social Indicators Research. 141, pp. 1307-1339.

Altieri, M.A. (2000) Multifunctional dimensions of ecologically-based agriculture in Latin America. The International Journal of Sustainable Development \& World Ecology. 7(1), pp. 62-75.

Arimond, M., Wiesmann, D., Becquey, E., Carriquiry, A., Daniels, M. C., Deitchler, M., Fanou-Fogny, N., Joseph, M.L., Kennedy, G., Martin-Prevel, Y., \& Torheim, L.E. (2010) Simple food group diversity indicators predict micronutrient adequacy 
of women's diets in 5 diverse, resource-poor settings. The Journal of Nutrition. 140(11), pp. 2059S-2069S.

Barling, D., Lang, T., \& Sharpe, R. (2010) The re-emergence of UK National Food Security on the policy agenda: Sustainability challenges and the politics of food supply. In: Lawrence, G. et al. (Eds.) Food security, nutrition and sustainability: New challenges, future options. London, Earthscan, pp. 61-78.

Barrett, C.B. (2010) Measuring food insecurity. Science. 327(5967), pp. 825-828.

Bell, S. \& Morse, S. (2013) Towards an understanding of how policy making groups use indicators. Ecological Indicators. 35, pp. 13-23.

Brunori, G. and Guarino, A. (2010) 'Security for whom? Changing discourses on food in Europe in times of a global food crisis', in Lawrence, G. et al (Eds.), Food security, nutrition and sustainability, Earthscan, London, pp. 41-60.

Convention on Biological Diversity (2004) Conference of the parties to the Convention on Biological Diversity. Decision adopted by the Conference of the Parties to the Convention on Biological Diversity - Seventh meeting Kuala Lumpur, 9-20 and 27 February 2004.

Conway, G. R. (1986) Agroecosystem analysis for research and development. Bangkok, Winrock International.

Department for Environment Food and Rural Affairs (2009) Indicators for a Sustainable Food System, DEFRA, London, England.

Dicks, L., Bardgett, R., Bell, J., Benton, T., Booth, A., Bouwman, J., Brown, C., Bruce, A., Burgess, P.J., Butler, S.J., Crute, I., Dixon, F., Drummond, C., Freckleton, R.P., Gill, M., Graham, A., Hails, R.S., Hallett, J., Hart, B., Hillier, G.J., Holland, J.M., Huxley, J.N., Ingram, J.S.I., King, V., MacMillan, T., McGonigle, D.F., McQuaid, C., Nevard, T., Norman, S., Norris, K., Pazderka, C., Poonaji, I., Quinn, C.H., Ramsden, S.J., Sinclair, D., Siriwardena, G.M., Vickery, J.A., Whitmore, A.P., Wolmer, W., \& Sutherland, W.J. (2013) What do we need to know to enhance the environmental sustainability of agricultural production? A prioritisation of knowledge needs for the UK food system. Sustainability. 5(7).

Drewnowski, A. \& Popkin, B.M. (1997) The nutrition transition: New trends in the global diet. Nutrition Reviews. 55(2), pp. 31-43.

Ericksen, P. (2008) Conceptualizing food systems for global environmental change research. Global Environmental Change. 18(1), pp. 234-245.

Ericksen, P., Ingram, J., \& Liverman, D.M. (2009) Food security and global environmental change: Emerging challenges. Environmental Science \& Policy. 12(4), pp. 373-377.

European Technology Platform (2008) European Technology Platform on Food for Life: Implementation action plan. Confederation of the food and drink industries of the EU, Brussels, Belgium.

Fanzo, J., Cogill, B., \& Mattei, F. (2012) Metrics of sustainable diets and food systems, technical brief-Madrid roundtable. Rome, Bioversity International.

FAO (2011) The State of Food Insecurity in the World 2011: How does international price volatility affect domestic economies and food security? FAO, Rome.

FAO \& Bioversity International (2012) Proceedings of the international scientific symposium: Biodiversity and sustainable diets united against hunger. Rome, FAO.

Feenstra, G., Jaramillo, C., McGrath, S., \& Grunnell, A.N. (2005) Proposed indicators for sustainable food systems. Portland, OR, Ecotrust. 


\section{Prosperi, Allen, \& Cogill}

Foran, T., Butler, J.R., Williams, L.J., Wanjura, W.J., Hall, A., Carter, L., \& Carberry, P.S. (2014) Taking complexity in food systems seriously: An interdisciplinary analysis. World Development. 61, pp. 85-101.

Gallopín, G.C. (1997) Indicators and their use: Information for decision-making. Part one - Introduction. In Moldan, B. \& Bilharz, S. Sustainability indicators. A report on the project on indicators of sustainable development. Chichester, Wiley.

Gallopín, G.C. (2003) A systems approach to sustainability and sustainable development. New York, United Nations Publications.

Hellegers, P., Zilberman, D., Steduto, P. and McCornick, P. (2008) 'Interactions between water, energy, food and environment: evolving perspectives and policy issues', Water Policy, Vol. 10, No. S1, pp. S1-S10.

HLPE. (2011) Price volatility and food security: a report by the High Level Panel of Experts on Food Security and Nutrition of the Committee on World Food Security, FAO, Rome, Italy.

HLPE (2014) Food losses and waste in the context of sustainable food systems. A report by the High Level Panel of Experts on Food Security and Nutrition of the Committee on World Food Security, FAO, Rome, Italy.

Ingram, J. (2011). A food systems approach to researching food security and its interactions with global environmental change. Food Security. 3(4), pp. 417-431.

IPCC (2012) Managing the risks of extreme events and disasters to advance climate change adaptation: Special report of the intergovernmental panel on climate change. Cambridge, Cambridge University Press.

Johnston, J.L., Fanzo, J.C., \& Cogill, B. (2014) Understanding sustainable diets: A descriptive analysis of the determinants and processes that influence diets and their impact on health, food security, and environmental sustainability. Advances in Nutrition: An International Review Journal. 5(4), pp. 418-429.

Kates R.W., Clark W.C., Corell, R., Hall, J.M., Jaeger, C.C., Lowe, I., McCarthy, J.J., Schellnhuber, H.J., Bolin, B., Dickson, N.M., Faucheux, S., Gallopin, G.C., Grübler, A., Huntley, B., Jäger, J., Jodha, N.S., Kasperson, R.E., Mabogunje, A., Matson, P., Mooney, H., Moore, B., O’ Riordan, T., \& Svedin, U. (2001) Sustainability science. Science. 292(5517), pp. 641-642.

Kearney, J. (2010) Food consumption trends and drivers. Philosophical Transactions of the Royal Society B: Biological Sciences. 365(1554), pp. 2793-2807.

Lopez-Legarrea, P., Fuller, N., Zulet, M., Martinez, J. and Caterson, I. (2014) 'The influence of Mediterranean, carbohydrate and high protein diets on gut microbiota composition in the treatment of obesity and associated inflammatory state', Asian Pacific Journal of Clinical Nutrition, Vol. 23, No. 3, pp. 360-368.

Meade, B. (2012) Global food markets. Washington, DC, USDA.

Metzger, M. \& Schröter, D. (2006) Towards a spatially explicit and quantitative vulnerability assessment of environmental change in Europe. Regional Environmental Change. 6(4), pp. 201-216.

Molden, D. (1997) Accounting for water use and productivity. Stockholm, IWMI.

OECD (2008) Handbook on constructing composite indicators: Methodology and user guide, Paris, OECD.

PARME. (2011) Quelles recherches et quels partenariats pour la Méditerranée? Atelier de Réflexion Prospective. Rapport final, Agropolis International, Montpellier, France.

Patel, A.C., Nunez, N.P., Perkins, S.N., Barrett, J.C., \& Hursting, S.D. (2004) Effects of energy balance on cancer in genetically altered mice. The Journal of Nutrition. 134(12), pp. 3394S-3398S. 
Perignon, M., Vieux, F., Soler, L.G., Masset, G., \& Darmon, N. (2017) Improving diet sustainability through evolution of food choices: Review of epidemiological studies on the environmental impact of diets. Nutrition Reviews. 75(1), pp. 2-17.

Pinstrup-Andersen, P. (2013) 'Nutrition-sensitive food systems: from rhetoric to action', The Lancet, Vol. 382, No. 9890, pp. 375-376.

Prosperi, P., Allen, T., Cogill, B., Padilla, M., \& Peri, I. (2016) Towards metrics of sustainable food systems: A review of the resilience and vulnerability literature. Environment Systems and Decisions. 36(1), pp. 3-19.

Prosperi, P., Allen, T., Padilla, M., Peri, I., \& Cogill, B. (2014) Sustainability and food \& nutrition security: A vulnerability assessment framework for the Mediterranean region. SAGE Open, 4(2). Available at: http://sgo.sagepub.com/ content/4/2/2158244014539169.full.pdf.

Regmi, A. and Meade, B. (2013) 'Demand side drivers of global food security', Global Food Security, Vol. 2, No. 3, pp.166-171.

Reidsma, P. and Ewert, F. (2008) 'Regional farm diversity can reduce vulnerability of food production to climate change', Ecology and Society, 13(1).

Robles, M., Torero, M., \& Von Braun, J. (2009) When speculation matters. International Food Policy Research Institute. Issue Brief 57, Washington, DC, IFPRI.

SCAR. (2011) 3rd SCAR foresight exercise: Sustainable food consumption and production in a resource-constrained world, Standing Committee on Agricultural Research, Foresight Expert Group, European Commission, Brussels.

Schlüter, M., Hinkel, J., Bots, P.W., \& Arlinghaus, R. (2014) Application of the SES framework for model-based analysis of the dynamics of social-ecological systems. Ecology and Society. 19(1). Available at: http://www.ecologyandsociety.org/ vol19/iss1/art36/.

Sébastien, L. \& Bauler, T. (2013) Use and influence of composite indicators for sustainable development at the EU-level. Ecological Indicators, 35, pp. 3-12.

Swinburn, B.A., Caterson, I., Seidell, J.C., \& James, W.P. (2004) Diet, nutrition and the prevention of excess weight gain and obesity. Public Health Nutrition. 7(1a), pp. 123-146.

Termote, C., Van Damme, P. and Dhed'a Djailo, B. (2010) 'Eating from the wild: Turumbu indigenous knowledge on noncultivated edible plants, Tshopo District, DR Congo', Ecology of food and nutrition, Vol. 49, No. 3, pp.173-207.

Thrupp, L.A. (2000) 'Linking agricultural biodiversity and food security: the valuable role of agrobiodiversity for sustainable agriculture', International Affairs, Vol. 76, No. 2, pp. 283-297.

Turner, B.L., Kasperson, R.E., Matson, P.A., McCarthy, J.J., Corell, R.W., Christensen, L., Eckley, N., Kasperson, J.X., Luers, A., Martello, M.L., Polsky, C., Pulsipher, A., \& Schiller, A. (2003) A framework for vulnerability analysis in sustainability science. Proceedings of the National Academy of Sciences. 100(14), pp. 8074-8079.

UNEP (2012) Measuring Progress: Environmental Goals \& Gaps, United Nations Environment Programme, Nairobi, Kenya.

United Nations [UN] (1987) Report of the world commission on environment and development: 'Our common future'. New York, United Nations.

United Nations [UN] (1996) Rome declaration on world food security. Rome, FAO.

UN-Water. (2014) The United Nations Water Development Report 2014: Water and Energy, UNESCO, Paris, France.

WHO (2008) WHO European Action Plan for Food and Nutrition Policy 20072012. World Health Organization Regional Office for Europe, Copenhagen. 


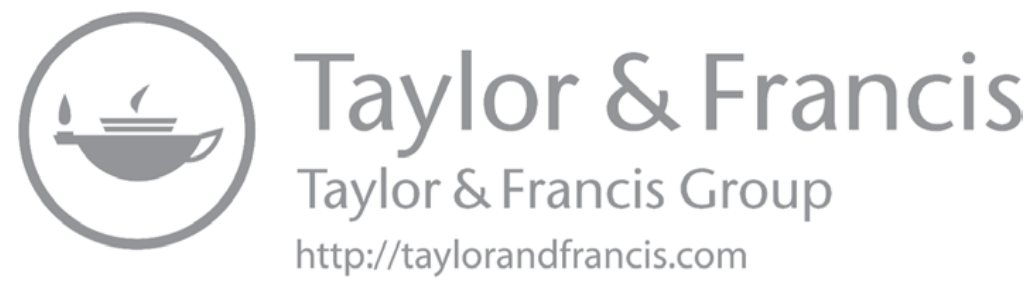

